Check for updates

Cite this: RSC Adv., 2017, 7, 29364

Received 11th May 2017

Accepted 25th May 2017

DOI: 10.1039/c7ra05351g

rsc.li/rsc-advances

\title{
Neutral linear supramolecular polymers constructed by three different interactions $\uparrow$
}

\author{
Qi Wang, ${ }^{\star a b}$ Peng Zhang, ${ }^{a}$ Yuanyuan Li, ${ }^{a}$ Lu Tian, ${ }^{a}$ Ming Cheng, ${ }^{b}$ Feng Lu, ${ }^{a}$ \\ Xiaomei Lu, ${ }^{c}$ Quli Fan ${ }^{\star a}$ and Wei Huang ${ }^{c}$
}

Neutral linear supramolecular polymers were efficiently constructed by the combination of quadruple hydrogen bonding, pillar[5]arene-based molecular recognition and $\pi-\pi$ donor-acceptor interactions. The disassembly of the supramolecular polymers can be effectively controlled by adding the competitive adiponitrile guest.

Supramolecular polymers, in which non-covalent interactions are always employed to hold the monomeric units together, not only exhibit polymer-like properties, but also possess new structures with unique functions such as stimuliresponsiveness, recyclability, self-healing and degradability. ${ }^{1}$ Therefore, supramolecular polymers are expected to provide a wide range of potential applications as functional adaptive materials. ${ }^{2}$ As we know, nature commonly utilizes the combination of different non-covalent interactions to create complicated and functionally ordered architectures such as DNA and so on. ${ }^{3}$ Motivated by this, scientists have been trying to fabricate supramolecular polymers with unprecedented properties and intriguing functions by self-assembly of multiple non-covalent interactions. ${ }^{4}$ For instance, Huang's group constructed a homogeneous linear supramolecular copolymer by orthogonal coordination-driven self-assembly, crown-ether-based [2] rotaxane host-guest interactions and quadruple hydrogen bonding of ureidopyrimidinone (UPy) in $2016 .{ }^{5}$ Recently, based on the unification of quadruple hydrogen bonding and crownether-based bistable [c2]daisy chain rotaxane molecular recognition, Giuseppone's group constructed a molecular-machinebased supramolecular polymer which could exhibit reversible sol-gel transitions, controlled by $\mathrm{pH}$ actuation. ${ }^{6}$

Pillararenes ${ }^{7}$ have captured more and more attention and provided a useful platform for the construction of

${ }^{a}$ Key Laboratory for Organic Electronics and Information Displays (KLOEID), Institute of Advanced Materials (IAM), Jiangsu National Synergetic Innovation Center for Advanced Materials (SICAM), Nanjing University of Posts \& Telecommunications, 9 Wenyuan Road, Nanjing 210023, China. E-mail: iamqwang@njupt.edu.cn; iamqlfan@njupt.edu.cn

${ }^{b}$ State Key Laboratory of Coordination Chemistry, School of Chemistry and Chemical Engineering, Nanjing University, Nanjing 210023, China

'Key Laboratory of Flexible Electronics (KLOFE), Institute of Advanced Materials (IAM), Jiangsu National Synergetic Innovation Center for Advanced Materials (SICAM), Nanjing Tech University (NanjingTech), 30 South Puzhu Road, Nanjing 211816, China $\dagger$ Electronic supplementary information (ESI) available: Synthetic procedures, characterizations, NMR spectra, and the calculation of binding constants. See DOI: $10.1039 / \mathrm{c} 7 \mathrm{ra} 05351 \mathrm{~g}$ supramolecular polymers ${ }^{8}$ because of their unique symmetrical pillar architecture, facile functionalization and adjustable hostguest properties. ${ }^{9}$ Until now, lots of pillararene-based neutral supramolecular polymers have been constructed by employing two kinds of non-covalent interactions. ${ }^{10}$ For example, Li's group provided a new strategy for the construction of neutral linear supramolecular polymers by the marriage of endo-cavity and exo-wall complexation of a pillar[5]arene in 2015. ${ }^{11}$ Recently, Shi's group constructed a novel linear supramolecular polymer by orthogonal pillar[5]arene-based molecular recognition, $\mathrm{Eu}(\mathrm{III})$-coordination and $\pi-\pi$ donor-acceptor interactions. ${ }^{12}$ However, to the best of our knowledge, pillar[5]arenebased neutral supramolecular polymers constructed by combining the themes of three non-covalent interactions are rare. Herein, we report novel neutral linear supramolecular polymers constructed by three kinds of non-covalent recognition motifs including quadruple hydrogen bonding, pillar[5] arene-based molecular recognition and $\pi-\pi$ donor-acceptor interactions. Firstly, we designed an unsymmetrical guest 1 possessing a UPy unit and a carbamate moiety, which can dimerize to form an unusual homoditopic AA-type supramonomer. According to Li's report, pillar[5]arene 2 binds with molecule 3 to form a $2: 1$ sandwich-type exo-wall complex driven by $\pi-\pi$ donor-acceptor interactions, which was seen as a homoditopic BB-type supramonomer. ${ }^{11}$ As a result, neutral linear supramolecular polymers were successfully constructed in the $\mathrm{A}_{2} \mathrm{~B}_{2}$ form as suggested in Scheme 1 .

A well-designed guest molecule 1, which bears a UPy unit and a carbamate moiety, was obtained in a moderate yield using commercially available starting materials according to the reported methods..$^{13}$ Initially, the host-guest interaction between 1 and 2 was investigated by ${ }^{1} \mathrm{H}$ NMR spectroscopy (Fig. 1, and S5, ESI $†$ ). As shown in Fig. 1a, in the spectrum of individual 1, the Upy $\mathrm{N}-\mathrm{H}$ signals showed large downfield shifts (between 10 and $13.5 \mathrm{ppm}$ ), which gave direct evidence for the dimerization of UPy units to form an unusual homoditopic AA-type supramonomer. ${ }^{14}$ After mixing $\mathbf{1}$ and 2, an evident upfield chemical 


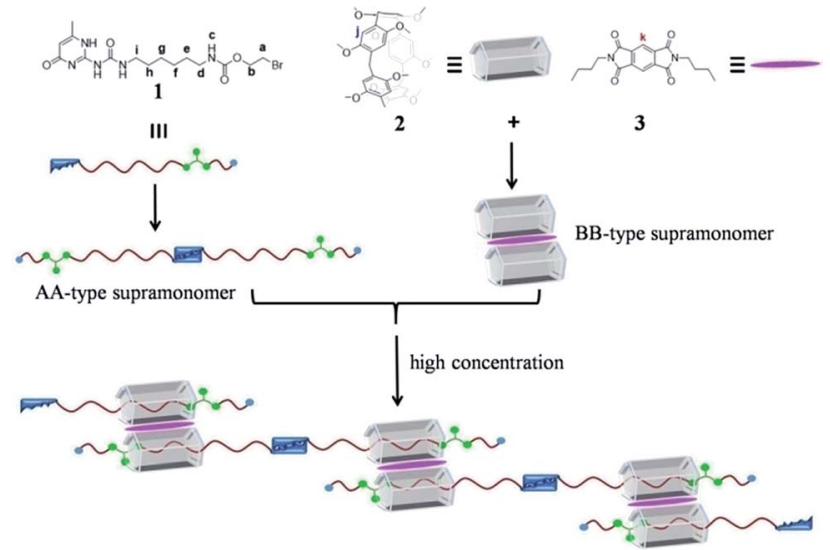

Scheme 1 The chemical structures of 1,2 and 3 and a cartoon representation of the formation of the neutral linear supramolecular polymers.

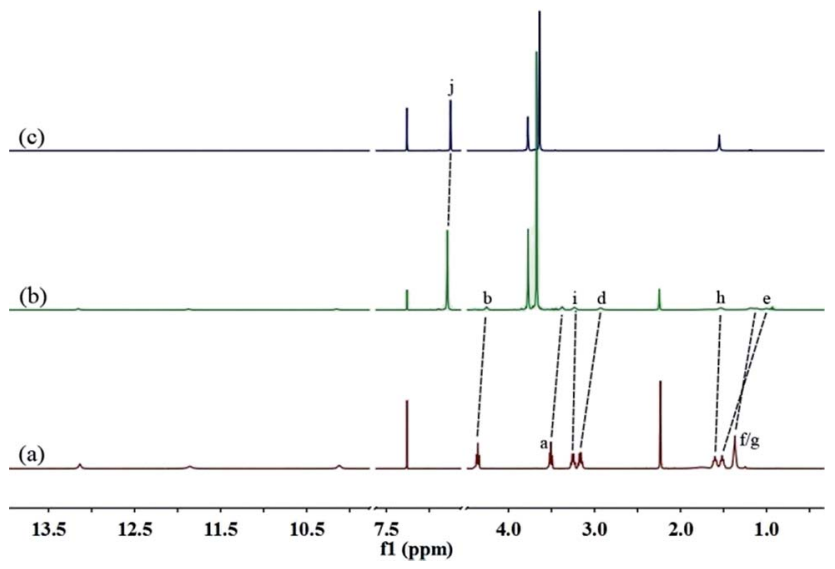

Fig. 1 Partial ${ }^{1} \mathrm{H}$ NMR spectra (400 MHz, CDCl $3,298 \mathrm{~K}$ ) of: (a) 1 (8.00 $\mathrm{mM})$; (b) 1 (8.00 mM) and 2 (12.00 mM); and (c) 2 (12.00 mM).

shift and a broadening effect of the methylene protons $\left(\mathrm{H}_{\mathrm{d}-\mathrm{g}}\right)$ on $\mathbf{1}$ were clearly observed, indicating that $\mathbf{1}$ threaded into the cavity of 2 .

Subsequently, two-dimensional ${ }^{1} \mathrm{H}$ NOESY was also carried out to study the self-assembly of $\mathbf{1}$ and 2 in $\mathrm{CDCl}_{3}$ solution. Correlation signals were observed between the methylene protons $\left(\mathrm{H}_{\mathrm{d}-\mathrm{i}}\right)$ of guest $\mathbf{1}$ and $\mathrm{H}_{\mathrm{j}}$ of host 2, indicating the formation of a host-guest inclusion complex between $\mathbf{1}$ and 2 (Fig. S6, ESI $\dagger$ ). In addition, a Job plot based on the ${ }^{1} \mathrm{H}$ NMR data demonstrated that the complex had $1: 1$ stoichiometry (Fig. S7, ESI†). By using a nonlinear curve-fitting analysis based on the ${ }^{1} \mathrm{H}$ NMR titration experiments, the association constant $\left(K_{\mathrm{a}}\right)$ of 2 $\supset 1$ was determined to be $85 \pm 4.1 \mathrm{M}^{-1}$ (Fig. S9, ESI $\dagger$ ).

As above-mentioned, the $2: 1$ sandwich-type complex between 2 and 3 formed via $\pi-\pi$ donor-acceptor interactions can be seen as a homoditopic BB-type supramonomer. Inspired by this, we investigated the possibility of constructing the neutral linear supramolecular polymers $\left(\mathbf{1}_{2} \cdot \mathbf{2}_{2} \cdot \mathbf{3}\right)$ by three kinds of non-covalent recognition motifs. Initially, when mixing $\mathbf{1}, \mathbf{2}$, and 3 in a 2:2:1 molar ratio in $\mathrm{CHCl}_{3}$ at low concentration, a pale red color from $\pi-\pi$ stacking between 2 and 3 appeared immediately. As the concentration increased, the color of the solution gradually became dark red (Fig. S10, ESI $\dagger$ ). Thereafter, concentration-dependent ${ }^{1} \mathrm{H}$ NMR spectroscopy was performed to reveal the possibility of generating the expected supramolecular polymers. As shown in Fig. 2, the large downfield chemical shifts and lower intensities observed on UPy $\mathrm{N}-\mathrm{H}$ indicated the dimerization of the UPy motifs. With increasing concentration, the signals of protons $\mathrm{H}_{\mathrm{a}-\mathrm{d}}$ of $\mathbf{1}$ and proton $\mathrm{H}_{\mathrm{k}}$ of 3 underwent substantial upfield shifts (Fig. 2, and S11, ESI†). Moreover, all the signals became broad at a high concentration, which confirmed the formation of aggregates with a high molecular weight. Diffusion-ordered ${ }^{1} \mathrm{H}$ NMR spectroscopy (DOSY) was further employed to confirm the formation of a concentration-dependent supramolecular polymer. As the concentration of the mixtures of 3 with 2 equiv. of 1 and 2 increased from $4.00 \mathrm{mM}$ to $50.0 \mathrm{mM}$, the measured weight average diffusion coefficient decreased significantly from 5.33 $\times 10^{-10} \mathrm{~m}^{2} \mathrm{~s}^{-1}$ to $2.65 \times 10^{-10} \mathrm{~m}^{2} \mathrm{~s}^{-1}$, suggesting the gradual formation of high-molecular-weight polymeric aggregates (Fig. 3). To further study the self-assembly process of $\mathbf{1}, \mathbf{2}$, and 3 to form the neutral linear supramolecular polymers, viscosity measurements were carried out in $\mathrm{CHCl}_{3}$ using a microUbbelohde viscometer. As presented in Fig. 4, the aggregates assembled from the monomers presented a viscosity transition, which was characterized by a change in the slope of the double logarithmic plots of the specific viscosity versus the concentration. In the low concentration range, the curve slope was 0.71 , which indicates the predominance of cyclic oligomers in dilute solutions. When the concentration exceeded the critical polymerization concentration (CPC, $7 \mathrm{mM}$ ), an obvious increase in the viscosity was observed (slope $=1.10$ ), suggesting a transition from small oligomers to larger linear supramolecular polymers. Moreover, large spherical aggregates were distinctly observed in the TEM image, which may have originated from further assembly of the linear supramolecular polymers (Fig. S12, ESI†े).

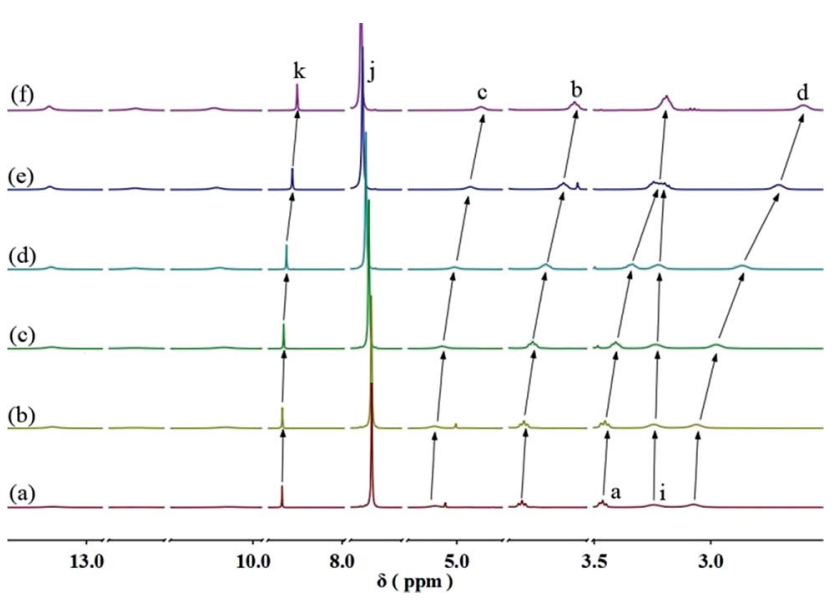

Fig. 2 Partial ${ }^{1} \mathrm{H}$ NMR spectra $\left(400 \mathrm{MHz} \mathrm{CDCl}_{3}, 298 \mathrm{~K}\right.$ ) of the mixed solution of 1,2 , and 3 in a $2: 2: 1$ molar ratio at different concentrations of 3: (a) 3; (b) 5; (c) 10; (d) 20; (e) 40; and (f) $50 \mathrm{mM}$. 


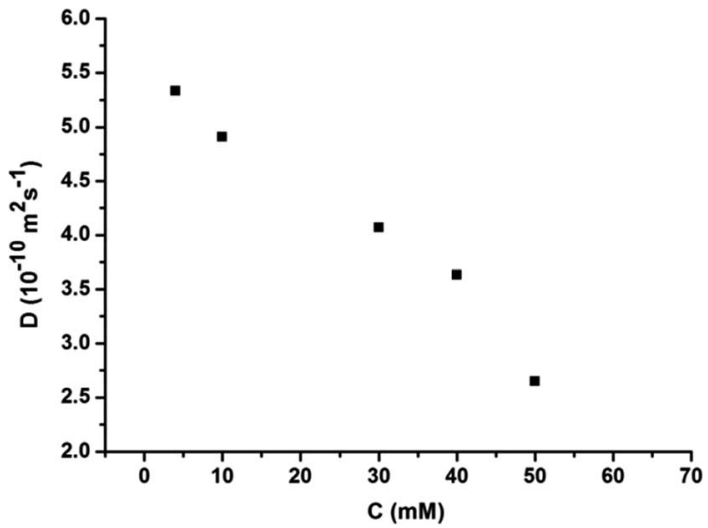

Fig. 3 The concentration dependence of the diffusion coefficient $D$ $\left(400 \mathrm{MHz}, \mathrm{CDCl}_{3}, 298 \mathrm{~K}\right.$ ) of the mixed solution of 3 and 2 equiv. of 1 and 2 .

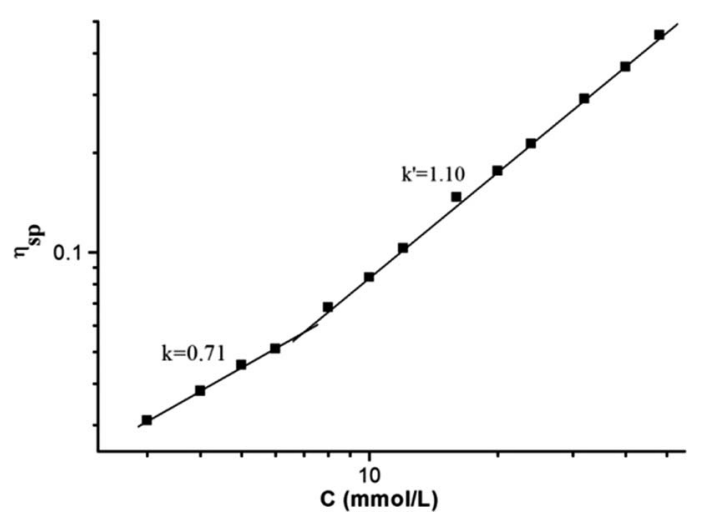

Fig. 4 The specific viscosity of the mixed solution of 3 and 2 equiv. of 1 and 2 versus the concentration of $3\left(\mathrm{CHCl}_{3}, 298 \mathrm{~K}\right)$.

Since pillar[5]arene shows very strong binding affinities with adiponitrile, ${ }^{15}$ we envisioned that the resulting neutral linear supramolecular polymers could be depolymerized by addition of a competitive guest. When 2.5 equiv. of adiponitrile was added into a solution of $3(10 \mathrm{mM})$ with 2 equiv. of 1 and 2 in $\mathrm{CDCl}_{3}$, the ${ }^{1} \mathrm{H}$ NMR signals of the free neutral guest $\mathbf{1}$ and the newly generated complex $2 \supset$ adiponitrile were observed, which confirmed the disassembly of the supramolecular polymers (Fig. 5 and S13, ESI $\dagger$ ).

In summary, we demonstrated that novel neutral linear supramolecular polymers composed of 1,2 , and 3 could be successfully constructed by combining three kinds of noncovalent recognition motifs including quadruple hydrogen bonding, pillar[5]arene-based molecular recognition and $\pi-\pi$ donor-acceptor interactions, and this was collectively confirmed by ${ }^{1} \mathrm{H}$ NMR, DOSY, viscosity, and TEM. Furthermore, the resulting supramolecular polymers can be effectively depolymerized by addition of a competitive guest. This work provides a new and convenient way to construct degradable supramolecular polymeric materials with tailored properties. Our future work will focus on developing more functional

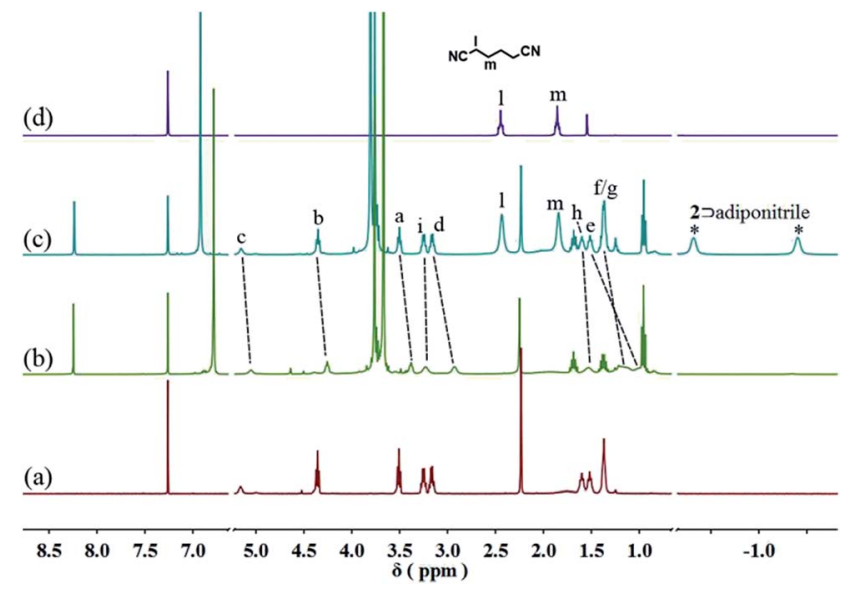

Fig. 5 Partial ${ }^{1} \mathrm{H}$ NMR spectra $\left(400 \mathrm{MHz}, \mathrm{CDCl}_{3}, 298 \mathrm{~K}\right.$ ) of (a) 1 ; (b) 3 (10 $\mathrm{mM}$ ) with 2 equiv. of 1 and 2 ; (c) after addition of 2.5 equiv. of adiponitrile to (b); and (d) adiponitrile. The asterisk symbols indicate complexed protons from 2 Jadiponitrile.

supramolecular polymers with rationally designed structures, by self-assembly of multiple non-covalent interactions.

\section{Acknowledgements}

This work was supported by the National Natural Science Foundation of China (Grant No. 21602112) and the China Postdoctoral Science Foundation (Grant No. 2017M611876), and sponsored by the Scientific Starting Fund from Nanjing University of Posts and Telecommunications (NUPTSF) (Grant No. NY215057) and the Natural Science Foundation of the Jiangsu Higher Education Institutions (Grant No. 16KJB150031).

\section{Notes and references}

1 (a) C. Fouquey, J.-M. Lehn and A.-M. Levelut, Adv. Mater., 1990, 2, 254; (b) C. Schmuck and W. Wienand, Angew. Chem., Int. Ed., 2001, 40, 4363; (c) T. F. A. D. Greef, M. M. J. Smulders, M. Wolffs, A. P. H. J. Schenning, R. P. Sijbesma and E. W. Meijer, Chem. Rev., 2009, 109, 5687; (d) M. Burnworth, L. Tang, J. R. Kumpfer, A. J. Duncan, F. L. Beyer, G. L. Fiore, S. J. Rowan and C. Weder, Nature, 2011, 472, 334; (e) E. A. Appel, J. del Barrio, X. J. Loh and O. A. Scherman, Chem. Soc. Rev., 2012, 41, 6195; (f) E. Elacqua, D. S. Lye and M. Weck, Acc. Chem. Res., 2014, 47, 2405; (g) L. Yang, X. Tan, Z. Wang and X. Zhang, Chem. Rev., 2015, 115, 7196; $(h)$ A. Winter and U. S. Schubert, Chem. Soc. Rev., 2016, 45, 5311.

2 (a) S. Burattini, B. W. Greenland, D. Chappell, H. M. Colquhoun and W. Hayes, Chem. Soc. Rev., 2010, 39, 1973; (b) T. Aida, E. W. Meijer and S. I. Stupp, Science, 2012, 335, 813; (c) N. L. Strutt, D. Fairen-Jimenez, J. Iehl, M. B. Lalonde, R. Q. Snurr, O. K. Farha, J. T. Hupp and J. F. Stoddart, J. Am. Chem. Soc., 2012, 134, 17436; (d) J. Tian, T.-Y. Zhou, S.-C. Zhang, S. Aloni, M. V. Altoe, S.-H. Xie, H. Wang, D.-W. Zhang, X. Zhao, Y. Liu and 
Z.-T. Li, Nat. Commun., 2014, 5, 5574; (e) R. Dong, Y. Zhou, X. Huang, X. Zhu, Y. Lu and J. Shen, Adv. Mater., 2015, 27, 498.

3 (a) E. Winfree, F. Liu, L. A. Wenzler and N. C. Seeman, Nature, 1998, 394, 539; (b) J. D. Hartgerink, E. Beniash and S. I. Stupp, Science, 2001, 294, 1684; (c) X. Yan, F. Wang, B. Zheng and F. Huang, Chem. Soc. Rev., 2012, 41, 6042; (d) S.-L. Li, T. Xiao, C. Lin and L. Wang, Chem. Soc. Rev., 2012, 41, 5950; (e) X. Yan, D. Xu, X. Chi, J. Chen, S. Dong, X. Ding, Y. Yu and F. Huang, Adv. Mater., 2012, 24, 362.

4 (a) R. J. Wojtecki, M. A. Meador and S. J. Rowan, Nat. Mater., 2011, 10, 14; (b) C.-H. Wong and S. C. Zimmerman, Chem. Commun., 2013, 49, 1679; (c) X. Ma and H. Tian, Acc. Chem. Res., 2014, 47, 1971; (d) X.-Y. Hu, T. Xiao, C. Lin, F. Huang and L. Wang, Acc. Chem. Res., 2014, 47, 2041; (e) P. Wei, X. Yan and F. Huang, Chem. Soc. Rev., 2015, 44, 815; $(f)$ D. S. Kim, J. Chang, S. Leem, J. S. Park, P. Thordarson and J. L. Sessler, J. Am. Chem. Soc., 2015, 137, 16038; $(g)$ Z. Zhou, X. Yan, T. R. Cook, M. L. Saha and P. J. Stang, J. Am. Chem. Soc., 2016, 138, 806.

5 P. Wei, X. Yan, T. R. Cook, X. Ji, P. J. Stang and F. Huang, ACS Macro Lett., 2016, 5, 671.

6 A. Goujon, G. Mariani, T. Lang, E. Moulin, M. Rawiso, E. Buhler and N. Giuseppone, J. Am. Chem. Soc., 2017, 139, 4923.

7 (a) T. Ogoshi, S. Kanai, S. Fujinami, T.-A. Yamagishi and Y. Nakamoto, J. Am. Chem. Soc., 2008, 130, 5022; (b) D. Cao, Y. Kou, J. Liang, Z. Chen, L. Wang and H. Meier, Angew. Chem., Int. Ed., 2009, 48, 9721; (c) C. Li, Chem. Commun., 2014, 50, 12420; (d) T. Ogoshi, T.-A. Yamagishi and Y. Nakamoto, Chem. Rev., 2016, 116, 7937; (e) S. Dasgupta and P. S. Mukherjee, Org. Biomol. Chem., 2017, 15, 762.

8 (a) M. Xue, Y. Yang, X. Chi, Z. Zhang and F. Huang, Acc. Chem. Res., 2012, 45, 1294; (b) H. Zhang and Y. Zhao, Chem.-Eur. J., 2013, 19, 16862; (c) N. L. Strutt, H. Zhang, S. T. Schneebeli and J. F. Stoddart, Acc. Chem. Res., 2014, 47, 2631; (d) Q. Wang, M. Cheng, Y. Zhao, L. Wu, J. Jiang, L. Wang and Y. Pan, Chem. Commun., 2015, 51, 3623; (e)
Q. Wang, M. Cheng, Y. Cao, J. Jiang and L. Wang, Acta Chim. Sin., 2016, 74, 9; $(f)$ Y. Wang, G. Ping and C. Li, Chem. Commun., 2016, 52, 9858.

9 (a) Z.-Y. Li, Y. Zhang, C.-W. Zhang, L.-J. Chen, C. Wang, H. Tan, Y. Yu, X. Li and H.-B. Yang, J. Am. Chem. Soc., 2014, 136, 8577; (b) C.-L. Sun, J.-F. Xu, Y.-Z. Chen, L.-Y. Niu, L.-Z. Wu, C.-H. Tung and Q.-Z. Yang, Chin. Chem. Lett., 2015, 26, 843; (c) K. Yang, Y. Pei, J. Wen and Z. Pei, Chem. Commun., 2016, 52, 9316; (d) C. Sathiyajith, R. R. Shaikh, Q. Han, Y. Zhang, K. Meguellati and Y.-W. Yang, Chem. Commun., 2017, 53, 677; (e) J. Murray, K. Kim, T. Ogoshi, W. Yao and B. C. Gibb, Chem. Soc. Rev., 2017, 46, 2479.

10 (a) X.-Y. Hu, P. Zhang, X. Wu, W. Xia, T. Xiao, J. Jiang, C. Lin and L. Wang, Polym. Chem., 2012, 3, 3060; (b) X.-Y. Hu, X. Wu, Q. Duan, T. Xiao, C. Lin and L. Wang, Org. Lett., 2012, 14, 4826; (c) X. Wang, K. Han, J. Li, X. Jia and C. Li, Polym. Chem., 2013, 4, 3998; (d) P. Chen, J. H. Mondal, Y. Zhou, H. Zhu and B. Shi, Polym. Chem., 2016, 7, 5221.

11 S. Wang, Y. Wang, Z. Chen, Y. Lin, L. Weng, K. Han, J. Li, X. Jia and C. Li, Chem. Commun., 2015, 51, 3434.

12 L. Shangguan, H. Xing, J. H. Mondal and B. Shi, Chem. Commun., 2017, 53, 889.

13 H. Hofmeier, A. El-ghayoury, A. P. H. J. Schenning and U. S. Schubert, Chem. Commun., 2004, 318.

14 (a) A. T. ten Cate and R. P. Sijbesma, Macromol. Rapid Commun., 2002, 23, 1094; (b) S.-L. Li, T. Xiao, Y. Wu, J. Jiang and L. Wang, Chem. Commun., 2011, 47, 6903; (c) X. Yan, T. R. Cook, J. B. Pollock, P. Wei, Y. Zhang, Y. Yu, F. Huang and P. J. Stang, J. Am. Chem. Soc., 2014, 136, 4460; (d) L. Wang, Z.-L. Gong, S.-Y. Li, W. Hong, Y. W. Zhong, D. Wang and L.-J. Wan, Angew. Chem., Int. Ed., 2016, 55, 12393; (e) Q. Wang, M. Cheng, J.-L. Jiang and L.-Y. Wang, Chin. Chem. Lett., 2017, 28, 793.

15 (a) X. Shu, S. Chen, J. Li, Z. Chen, L. Weng, X. Jia and C. Li, Chem. Commun., 2012, 48, 2967; (b) J. Wu, S. Sun, X. Feng, J. Shi, X.-Y. Hu and L. Wang, Chem. Commun., 2014, 50, 9122; (c) X. Wu, M. Ni, W. Xia, X.-Y. Hu and L. Wang, Org. Chem. Front., 2015, 2, 1013. 